\title{
Анализ показателей психоэмоционального состояния кадетов после реализации средств саморегуляции
}

Логинов А.А. ${ }^{1}$, Кузнецова 3.М. ${ }^{2 *}$, Мутаева И.ШІ.

${ }^{2}$ Тюменское президентское кадетское училище министерства обороны Российской Федерации 2. Тюмень, Россия

ORCID: oooo-ooo1-9931-7742, La-1809@bk.ru

${ }^{2}$ Набережночелнинский филиал Университета управления «ТИСБИ»

г. Набережные Челны, Россия

ORCID: oooo-ooo2-5558-474X, kzm diss@mail.ru

${ }^{3}$ Елабужский институт (филиал) Казанского (Приволжского) федерального университет г. Елабуга, Россия,

ORCID: oooo-ooo2-9387-7033, mutaeva-i@mail.ru

Аннотация: Психоэмоциональное состояние, рассматриваемое как часть проявления психического состояния спортсменов в различных видах спорта, требует регуляции за счет использования адекватных средств с учетом условий их применения. Занятия полиатлоном подразумеваютпланирование тренировочных воздействий различной направленности, которые требуют высокого уровня проявления устойчивости, особенно психоэмоционального состояния. Тренировочные воздействия и соревновательная деятельность требуют серьезного отношения к психологической подготовке кадетов, совершенствования значимых свойств личности путем эффективного формирования системы отношений к деятельности. Материальц. Сравнительный анализ абсолютных средних значений показателей психоэмоционального состояния кадетов до и после использования психорегулирующих средств. Методъ исследования. Анализ и обобщение научной литературы; диагностика психоэмоционального состояния кадетов с использованием активациометра (аппарат «АЦ-9К»), эксперимент, методы математической статистики. Результатъ. Результаты исследования показали, что анализ психоэмоционального состояния кадетов в процессе занятий полиатлоном выступает условием эффективной спортивной подготовки. Исследование устойчивости к повышающимся физическим и умственным нагрузкам позволяет своевременно провести коррекцию их психоэмоционального состояния. Основными задачами подготовки кадетов средствами полиатлона являются воспитание моральных качеств, преданности Родине, чувства команды, трудолюбия. При этом устойчивость в психоэмоциональном состоянии является важным фактором контроля устойчивости организма к нервным и физическим перегрузкам, который особенно часто проявляется у кадетов первого года обучения в условиях образовательногоучреждения. Важную роль при физическом воспитании кадетов играет соревновательная деятельность, в связи с чем актуализируется формирование высокого уровня ответственности за команду, ответственности перед коллективом за счет саморегуляции психического состояния и воспитания волевых качеств. Заключение. Проведенный анализ показателей, характеризующих психоэмоциональное состояние кадетов после реализации комплекса психорегулирующих средств и средств релаксации, показал, что психоэмоциональным состоянием можно эффективно управлять. Процесс комплексного отбора кадетов к занятиям полиатлоном требует учета не только физических показателей, но и показателей, характеризующих типологию нервной системы кадетов.

Ключевые слова: кадеты, психоэмоциональное состояние, устойчивость, нагрузка, средства саморегуляции, психическое состояние.

Для цитирования: Логинов А.А., Кузнецова 3.М.*, Мутаева И.Ш. Анализ показателей психоэмоционального состояния кадетов после реализации средств саморегуляции. Педагогикопсихологические и медико-биологические проблемы физической культуры и спорта. 2020; 15(4): 84-90. DOI: $10.14526 / 2070-4798-2020-15-4-84-90$

\section{Psycho-emotional state indices analysis among cadets after self-regulation means realization}


Aleksandr A. Loginov ${ }^{1}$, Zinaida M. Kuznetsova ${ }^{2 *}$, Ilsiyar Sh. Mutaeva ${ }^{3}$ ${ }^{1}$ Tyumen Presidential Cadet College of the Ministry of Defense of the Russian Federation Tyumen, Russia

ORCID: oooo-ooo1-9931-7742,La-1809@bk.ru

${ }^{2}$ Naberezhnye Chelny branch of the University of Management "TISBI"

Naberezhnye Chelny, Russia

ORCID: oooo-00o2-5558-474X, kzm diss@mail.ru

${ }^{3}$ Yelabuga Institute (branch) of Kazan (Volga region) Federal University

Yelabuga, Russia,

ORCID: oooo-ooo2-9387-7033, mutaeva-i@mail.ru

\begin{abstract}
Psycho-emotional state, considered as the part of psychic state demonstration in different kinds of sport, demands regulation by means of adequate means, taking into account the conditions of its use. Polyathlonprovides training influences of different orientations planning. They demand high level of steadiness, especially psycho-emotional state resistance. The training loads and competitive activity demand serious attitude to cadets' psychological training, important personality features development by means of an effective system of attitude to activity formation. Materials. Comparative analysis of absolute average values of cadets' psycho-emotional state before and after psycho-regulating means use. Research methods. Information sources analysis and summarizing; cadets' psycho-emotional state diagnostics using activationmeter ("ATS-9K" apparatus), experiment, methods of mathematical statistics. Results. The research results showed that cadets' psycho-emotional state analysis during polyathlon lessons presented the condition of an effective sports training. Studying resistance to the increasing physical and mental loads helps to correct timely cadets' psycho-emotional state. The main objectives of cadets' training by means of polyathlon are the following: moral qualities, dedication to Motherland, sense of team, diligence upbringing. At the same time, resistance in psycho-emotional state is an important factor of organism resistance control to nervous and physical overloads. It is very often revealed among cadets of the first year of study in terms of an educational establishment. Competitive activity plays an important role in cadets' physical upbringing. In this connection it is important to form high level of responsibility for the team, for collective by means of psychic state self-regulation and volitional qualities upbringing. Conclusion. The held indices analysis, characterizing cadets' psycho-emotional state after the complex of psycho-regulating means and means of relaxation, showed that it is possible to realize an effective control over psycho-emotional state. The process of a complex selection among cadets for polyathlon lessons demands taking into account not only physical indices, but also the indices, which characterize the type of cadets' nervous system.
\end{abstract}

Keywords: cadets, psycho-emotional state, resistance, load, self-regulation means, psychic state.

For citation: Aleksandr A. Loginov, Zinaida M. Kuznetsova*, Ilsiyar Sh. Mutaeva. Psycho-emotional state indices analysis among cadets after self-regulation means realization. Russian Journal of Physical Education and Sport. 2020; 15(4): 84-90. DOI: 10.14526/2070-4798-2020-15-4-84-90

\section{ВВЕДЕНИЕ}

Психоэмоциональное

состояние,

рассматриваемое как часть проявления психического состояния спортсменов в различных видах спорта, требует регуляции за счет использования адекватных средств с учетом условий их применения $[1,2,4,5]$.

Занятия полиатлоном подразумевают планирование тренировочных воздействий различной направленности, которые требуют высокого уровня проявления устойчивости, особенно психоэмоционального состояния кадетов. Тренировочные воздействия и соревновательная деятельность требуют серьезного отношения к психологической подготовке кадетов, совершенствуя при этом значимые свойства личности путем эффективного формирования системы отношений к деятельности.

В современном полиатлоне важным является успешное выступление в соревнованиях различного ранга. Подготовка кадетов к выступлениям имеет свои особенности. Это зависит, прежде всего, от видов полиатлона. Тактическая схема подготовки кадетов к соревновательнойдеятельностирассматривается 
с учетом различных сторон подготовки. При этом интегральная подготовка занимает особое место [8,9,10]. Успешность соревновательной деятельности, особенно в стрельбе, зависит от психического состояния контроля над своими движениями. В стрельбе побеждает тот, кто может быстрее сосредоточиться и выдержать все фазы стрельбы. В соревнованиях по полиатлону побеждает тот, кто более подготовлен всесторонне. При одинаковых уровнях подготовленности кадетов эмоциональное состояние занимает особое место.

В связи с этим психологическая подготовка кадетов важна в условиях училищ военного типа. В первую очередь, это выявление и подбор наиболее одаренных кадетов для выступления на соревнованиях.

Отбор кадетов к систематическим занятиям для сборной команды требует особого подхода к этому процессу. Необходимо, вопервых, учитывать типологические особенности характера кадетов, тип темперамента; во-вторых, определить уровень развития физических качеств; в-третьих, определить функциональные возможности организма кадетов в возрастном аспекте.

Комплексный подход к отбору для тренировочных занятий по полиатлону позволяет отобрать кадетов, наиболее подготовленных к восприятию большого объема информации, оценке обстановки и систематическим тренировкам. У кадетов можно воспитывать исключительно тонкий тип восприятия боевой (соревновательной) обстановки.

В подготовке кадетов существует потребность в новых методах обследования, позволяющих проводить регулярный эффективный мониторинг не только физического, но и психического состояния.

Целью данной работы явилось проведение сравнительного анализа абсолютных средних значений показателей психоэмоционального состояния кадетов до и после использования психорегулирующих средств.

\section{МАТЕРИАЛЫ И МЕТОДЫ}

Опытно-экспериментальная работапо проблеме исследования проводилась с 2018 года в Тюменском президентском кадетском училище МО РФ. В эксперименте приняли участие кадеты, вошедшие в возрастные группы обучения 14-15 лет, 16-17 лет, 18-19 лет, занимающиеся полиатлоном. Проведена оценка психоэмоционального состояния по показателям: точности реакции на движущий объект, коэффициента силы нервной системы, количества движений, времени прохождения диагностик, коэффициентачувстватемпа,уровня избирательности внимания, координации мышц сгибателей и разгибателей. Для проведения диагностики психоэмоционального состояния кадетов использован активациометр (аппарат «АЦ-9К») [7]. Проведена реализация комплекса средств саморегуляции психического состояния кадетов с учетом исходного уровня проявления показателей, характеризующих психоэмоциональное состояние. Основными средствами, включенными в методику, явились аутотренинг, идеомоторная тренировка, визуализация желаний и потребностей, переключение внимания и психо-мышечная тренировка в сочетании с дыхательными упражнениями.

\section{РЕЗУЛЬТАТЫ И ОБСУЖДЕНИЕ}

В период 2018/2019 учебного года проведено исследование психоэмоционального состояния кадетов. Проведен сравнительный анализ психоэмоционального состояния кадетов по показателям: точности реакции на движущий объект, коэффициента силы нервной системы, количества движений, времени прохождения диагностики, коэффициента чувства темпа, уровня избирательности внимания, координации мышц сгибателей и разгибателей.

Результаты, полученные в период эксперимента, представлены на рис. 1-8. 


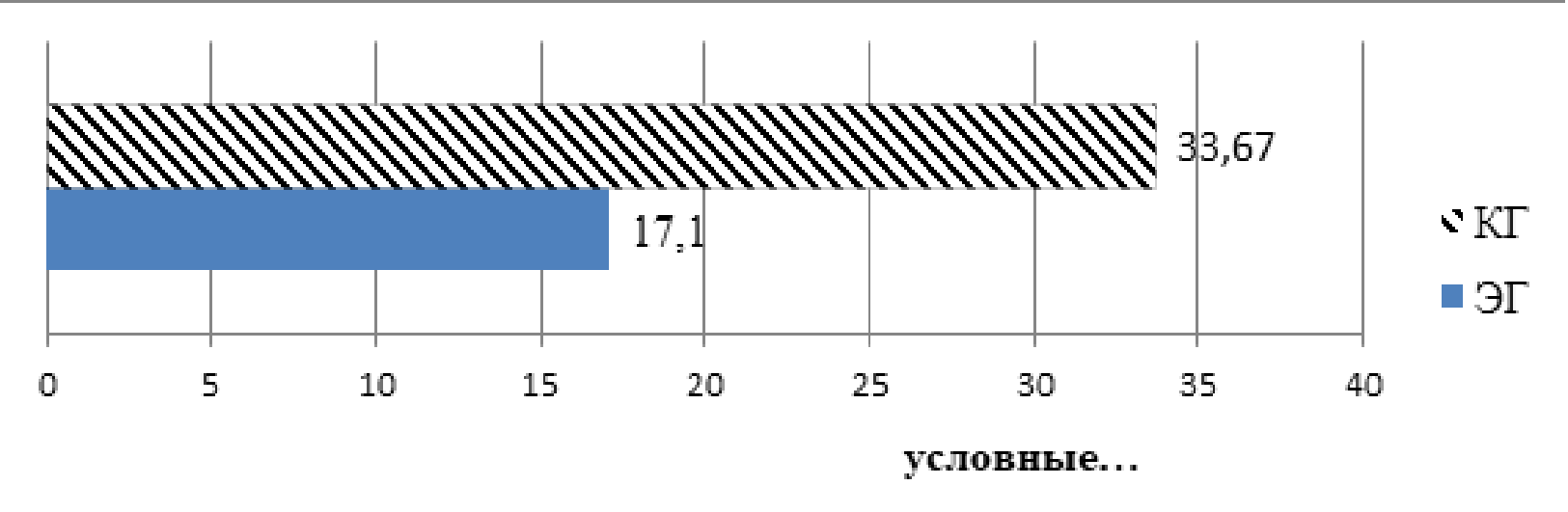

Рисунок 1. Показатели точности реакции на движущийся объект (ТРДО), ус.ед.

На рисунке 1 представлены показатели, характеризующие точность реакции на движущийся объект, кадетов исследуемых групп. Реакция на движущийся объект кадетов контрольной и экспериментальной групп после реализации методики психорегуляции психоэмоционального состояния до соревнований значимо различаются. В группе кадетов ЭГ исходный показатель ТРДО

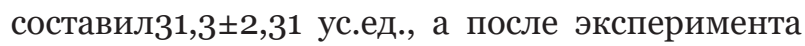
изменился значимо достоверно и равнялся
17,1土2,31 ус.ед.

В контрольной группе кадетов исходный

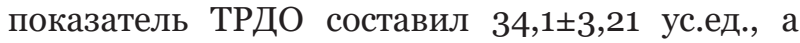
после эксперимента он изменился значимо достоверно и равнялся $33,67 \pm 1,63$ ус.ед.

На рис. 2 представлен коэффициент силы нервной системы, определяющий функциональную асимметрию нервной системы. Данный показатель дает возможность определить работоспособность нервной системы кадетов.

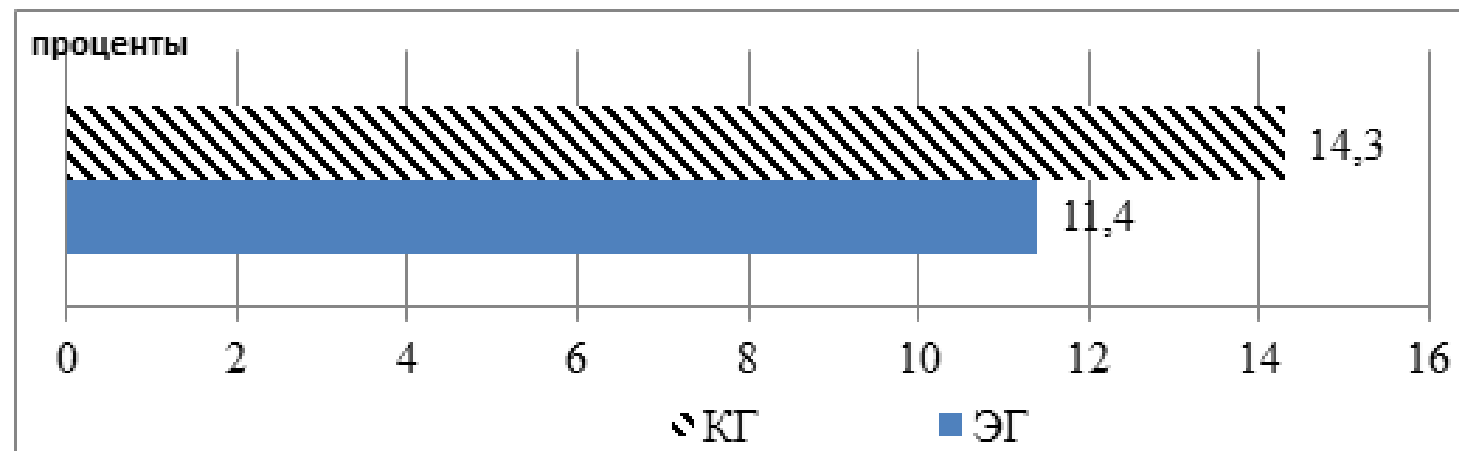

Рисунок 2. Показатели коэффициента силы нервной системы (КсHC), \%

На рис. 2 наглядно представлены возможности организма. В процессе показателикоэффициентасилынервнойсистемы кадетов контрольной и экспериментальной групп. В ЭГ кадетов КсНС при равных условиях в начале эксперимента составил $11,4 \%$, а у кадетов КГ - 14,3.Сила и слабость нервной системы кадетов характеризуется проявлением устойчивости к возрастающим физическим занятий полиатлоном требуется проявление выносливости кадетов к возрастающим нагрузкам.

На рисунках 3,4 представлены показатели количества движений кадетов и координация мышц-сгибателей. нагрузкам с проявлением возбуждения или торможения, атакже уравновешенностью или неуравновешенностью процессов нервной системы. Проявление у кадетов различных комбинаций силы и слабости нервной системы позволяет выявлять и учитывать адаптационные 


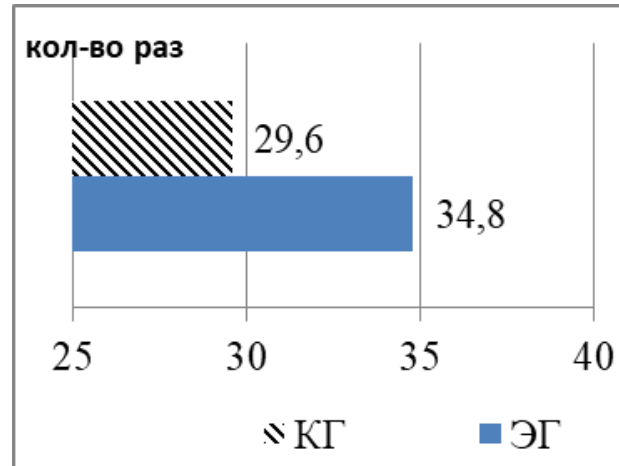

Рисунок 3. Показатели количества движений кадетов

В процессе занятий физическими упражнениями происходит улучшение проявлений скорости и точности. От качества их проявления зависит возникновение различных состояний, сопровождающих работу человека (врабатывание, монотония, психическое пресыщение, утомление). В процессе напряжения психического и психоэмоционального состояния время простой реакции увеличивается. Отмечено, что количество движений, как и качество их выполнения, может изменяться в зависимости от требований деятельности. Количество движений и координации мышц имеют нелинейные связи с силой нервной системы. Оно наименьшее у лиц со слабой и сильной нервной системой, а больше всего у лиц со средней силой нервной системы [1].

В показателях координации движений (КолД) кадетов наблюдается достоверное изменение в ӘГ (рисунок 3).

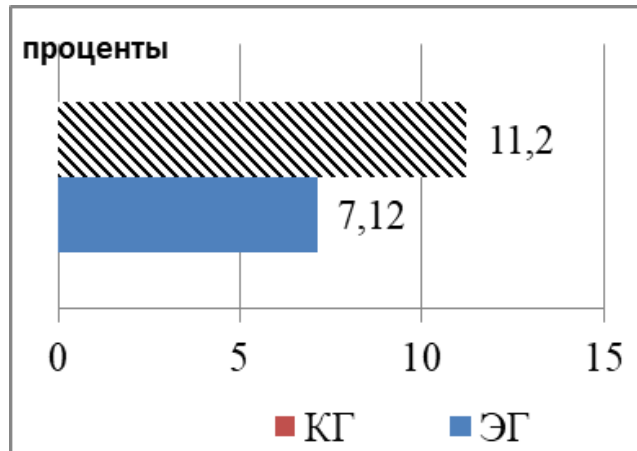

Рисунок 4. Показатели координации мышцсгибателей кадетов

Показатели коэффициента мышцсгибателей и разгибателей в ЭГ кадетов достоверно выше в конце эксперимента $-7,12 \pm 1,88 \%$. В КГ кадетов не наблюдаются значимые изменения в показателях Ккор МСи отмечены достоверно значимые различия по сравнению с ЭГ кадетов (рисунок 4).Вычисляя разность между координацией мышцразгибателей и мышц-сгибателей кадетов, мы определили дельту между координацией мышцразгибателей и мышц-сгибателей. Диагностика данного показателя по диагностической шкале Ю.А. Цагарелли, (2002) позволила определить, что у кадетов ЭГ координация мышц-сгибателей изменяется в лучшую сторону со знаком«+», а в КГ кадетов - со знаком «-»,координация мышцсгибателей хуже.

На рис. 5-7 наглядно представлены показатели уровня избирательности внимания, времени прохождения диагностики и коэффициента чувства темпа.

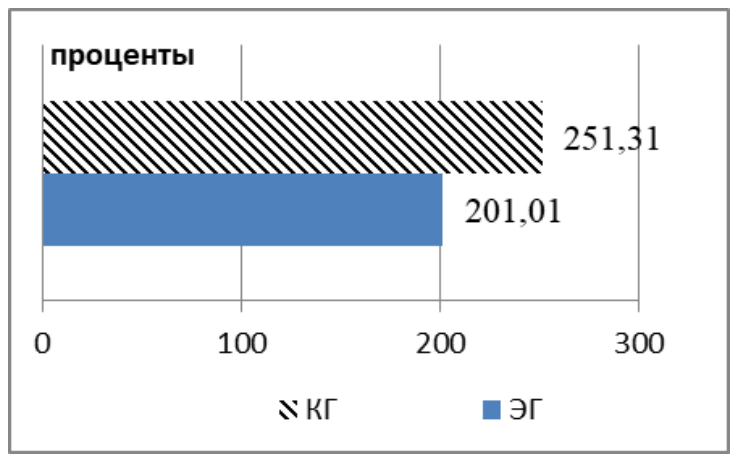

Рисунок 6. Показатели времени прохождения диагностики кадетов после эксперимента 
Показатель уровня избирательности внимания кадетов изменяется после воздействий психорегулирующих тренировок с использованием комплекса релаксационных упражнений сразу после тренировочных занятий.

Уровень избирательности внимания кадетов ЭГ после экспериментасоставил

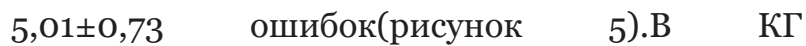
кадетовуровень избирательности внимания

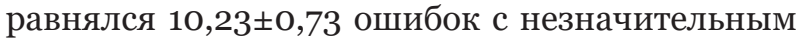
изменением по сравнению с исходными

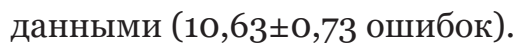

Достоверные изменения наблюдаются в показателях диагностики чувства темпа (КЧТ) у кадетов ЭГ (рис. 7).

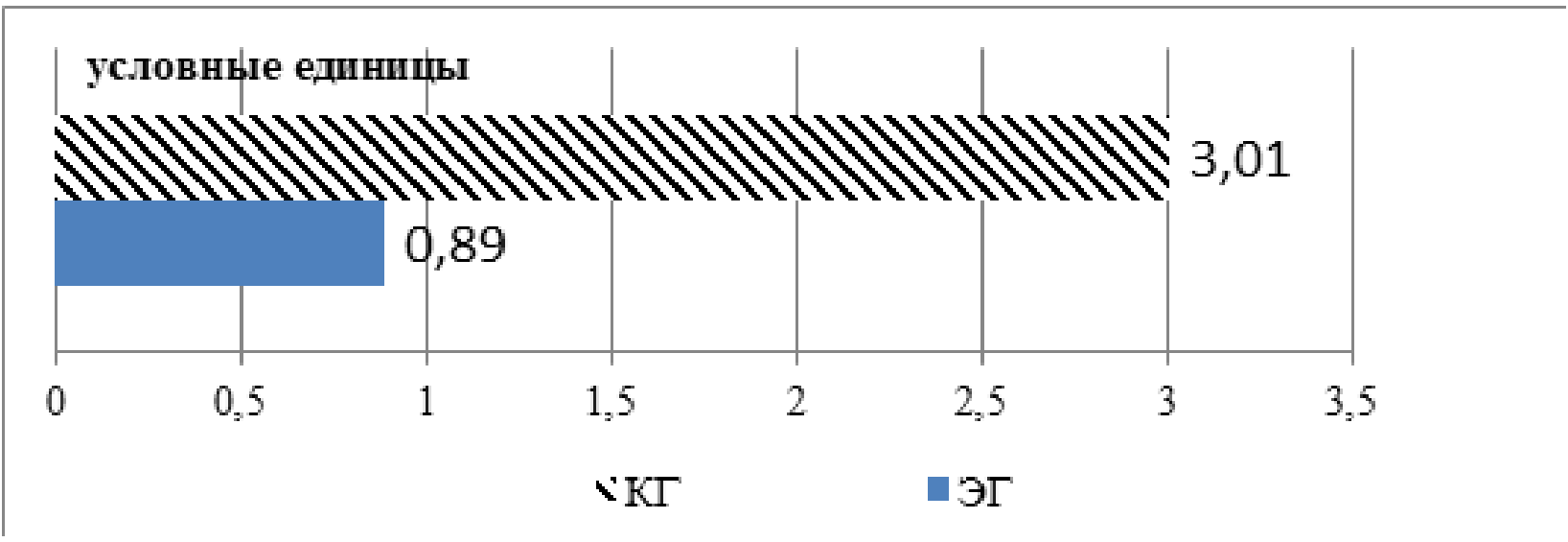

Рисунок 7. Показатели коэффициента чувства темпа кадетов

Если вначале эксперимента в ЭГ

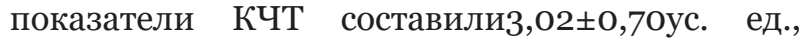
то в конце $-0,89 \pm 0,32 y c$. ед. В КГ показатели остались чуть ниже среднего уровня и составили в начале эксперимента 3,22 $\pm 0,45$ ус. ед., в конце

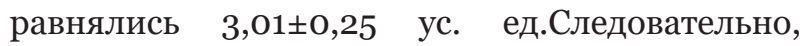
восстановительные мероприятия, применяемые после тренировочных занятий, оказывают благоприятное воздействие на психоэмоциональное состояние кадетов ЭГ.

\section{ЗАКЛЮЧЕНИЕ}

Таким образом, проведенный анализ показателей, характеризующих психоэмоциональное состояние кадетов после реализации комплекса психорегулирующих средств и средств релаксации, показал, что психоэмоциональным состоянием можно эффективно управлять.

Процесс комплексного отбора кадетов к занятиям полиатлоном требует учета не только физических показателей, но и показателей, характеризующих типологию нервной системы кадетов.

\section{СПИСОК ЛИТЕРАТУРЫ:}

1. Гордон С.М., Ильин А.Б. Оценка психологической готовности. Теория ипрактика физической культуры. 2004; 2: 45-49.

2. Закиров Д.Р., Кузнецов А.С. Сравнительный анализ состояния психической готовности борцов греко-римского стиля в период соревнований. Физическая культура и спорт - наука и практика. 2013; 1: 37-42.

3. Ильин Е.П. Психология спорта. Л.: Питер. 2008: 352.

4. Камалиева Г.А., Кузнецова 3.M. Модель подготовки волейболистов к преодолению препятствий и трудностей, неожиданно возникающих в соревновательной деятельности. Педагогико-психологические и медико-биологические проблемы физической культуры и спорта. 2011; 2(19): 38-44.URL: http://journalsport.ru/images/vipuski/6-1/2.pdf.

5. Смоленцева В.Н. Психическая саморегуляция в процессе подготовки спортсменов. Омск: СибГУФК. 2003.

6. Смирнова В.В. Психологическое сопровождение подготовки борцов высокой квалификации. Теория u практика физ. культуры: Тренер: журнал в журнале. 2010; 6: 66-68.

7. Цагарелли Ю.А. Системная психологическая диагностика на приборе «Активациометр»: учебное пособие. Казань.: ИУӘиП. 2004: 250.

8. Кузнецов А.С., Кузнецова 3.М. II Съезд членов общественной организации «Российское профессорское собрание». Педагогикопсихологические и медико-биологчческие проблемы физической культуры и спорта. 
2019; 14(4): 5-7. DOI: $10.14526 / 2070-4798-2019-$ $14-4-5-7$

9. Craig C.L., Marshall A.L., Sjostrom M., Bauman A.E., Booth M.L., Ainworth B.E., ..., Oja P. International Physical activity questionnaire: 12-Country reliability and validity. Medicine and Science in Sports and Exercise. 2003; 35: 1381-
1395. DOI: 10.1249/01.MSS.0000078924.61453. FB.

10. Daskapan A., Tuzun E.H., Eker L. Relationship between physical activity level and health related quality of life among university students. Saudi Medical Journal. 2005; 26: 10261028.

\section{Статья поступила в редакцию: 15.09.2020}

Логинов Александр Александрович - стариий преподаватель, Тюменское президентское кадетское училище министерства обороны Российской Федерации, 625оо1, Россия, г. Тюмень, ул. Льва Толстого, дом 1, e-mail: yulyaloginova@myrambler.ru

Кузнецова Зинаида Михайловна - доктор педагогических наук, профессор, Набережночелнинский филиал Университета управления «ТИСБИ», 4238о6, Россия, г. Набережные Челны, ул. Комсомольская набережная, дом 6, e-mail: kzm diss@mail.ru

Мутаева Ильсияр Шафиковна -кандидат биологических наук, профессор, Елабужский институт (филиал) Казанского федерального университета, 4236оо, Россия, г. Елабуга, ул. Казанская, дом 89, e-mail: mutaeva-i@mail.ru 